\title{
CHEMOSPHERE
}

\section{Modeling VOCs adsorption onto activated carbon}

\author{
C.L. Chuang ${ }^{\text {a }}$, P.C. Chiang ${ }^{\text {a,* }}$, E.E. Chang ${ }^{b}$ \\ a Graduate Institute of Environmental Engineering, National Taiwan University, 71 Chou-Shan road, Taipei, Taiwan \\ b Department of Biochemistry, Taipei Medical University, Taipei, Taiwan
}

Received 15 October 2002; received in revised form 26 February 2003; accepted 25 March 2003

\begin{abstract}
The activated carbon adsorption process is affected by the characteristics of adsorbent, adsorbate and environmental conditions. In this study, both adsorption and desorption processes are assumed to occur simultaneously and a numerical model was developed with a non-linear driving force in conjunction with the Langmuir model for predicting the overall adsorption process. The numerical model provides both adsorption and desorption rate constants and activation energies. The resultant equilibrium constants are of the same order of magnitude as reported by other studies. Results show that the model could well predict the adsorption isotherms and breakthrough curves under various conditions.
\end{abstract}

(C) 2003 Elsevier Ltd. All rights reserved.

Keywords: Activated carbon; VOCs; Adsorption; Desorption; Kinetics

\section{Introduction}

Activated carbon is a common adsorbent for the removal of hazardous pollutants. It has been reported that factors, such as characteristics of activated carbon, the nature and concentration of adsorbates, and reaction conditions including temperature and humidity, can affect the adsorption process. Pressure swing adsorption and thermal swing adsorption are the most common methods used to study the adsorption process (Hwang and Lee, 1994). King and Do (1996) used the Fourier transfer-infrared technique to evaluate the effect of temperature on the adsorption capability of ethane, propane, and $n$-butane onto activated carbon. They reported that the equilibrium time at high temperatures was shorter than that at low temperatures. Wood (1992) observed a good correlation between the molar polarization of adsorbent and adsorption capacity. Other researchers (Jonas and Rehrmann, 1972; Vahdat et al.,

\footnotetext{
${ }^{*}$ Corresponding author. Fax: +886-2-23661642.

E-mail address: pcchiang@ntu.edu.tw (P.C. Chiang).
}

1995) considered the activated carbon bed adsorption process as a first-order reaction and found the Wheeler equation to be successful for application to several organic gases.

For the column adsorption studies, the most commonly used adsorption models include the linear driving force (LDF) approximation (Gkueckauf, 1955; Crittenden and Weber, 1978; Malek and Farooq, 1996, 1997), the empirical method (Yoon and Nelson, 1984), and the Wheeler equilibrium approach (Jonas and Rehrmann, 1972; Vahdat, 1997) (Table 1). According to the LDF method, the reaction rate is governed by the difference between the temporal and the equilibrium concentrations of the gas adsorbate (Gkueckauf, 1955). The LDF model was utilized with a linear or non-linear equilibrium adsorption isotherm for practical consideration (Malek and Farooq, 1996, 1997). Hwang and Lee (1994) used the LDF model to successfully describe the adsorption and desorption behavior of carbon monoxide and carbon dioxide onto activated carbon. Yoon and Nelson (1984) developed an empirical model to predict the breakthrough curve of activated carbon beds. Based on the thermodynamic characteristic of each solute at 
Table 1

Adsorption models

\begin{tabular}{lll}
\hline Column adsorption model & Typical model equation & Reference \\
\hline Linear driving force approximation & $\frac{\partial q}{\partial t}=k\left(q^{*}-q\right)$ & $\begin{array}{l}\text { Gkueckauf (1955), Crittenden and Weber (1978), } \\
\text { Malek and Farooq (1996, 1997) }\end{array}$ \\
Empirical method & $t=t_{1 / 2}+\frac{1}{k^{\prime}} \ln \left(\frac{C}{C_{0}-C}\right)$ & Yoon and Nelson (1984) \\
& $k^{\prime}=\frac{k C Q}{W_{\mathrm{e}}}$ & \\
$t_{1 / 2}=t$ when $C=C_{0} / 2$ & \\
Wheeler equation & $t=\frac{W_{\mathrm{e}}}{C Q}\left[W-\frac{\rho_{\mathrm{B}} Q}{k} \ln \left(\frac{C_{0}}{C}\right)\right]$ & Jonas and Rehrmann (1972), Vahdat (1997) \\
\hline
\end{tabular}

equilibrium, Myers and Prausnitz (1965) developed an ideal adsorbed solution theory to predict the adsorption of organic vapors onto activated carbon. The adsorption equilibrium of the gas mixture can be predicted from the individual single-gas isotherm using the Toch equation (Myers and Valenzuela, 1986) and/or the Dubinin/ Radushkevich equation (Dubinin, 1989). The desorption behavior of carbon films was also observed based on the Arrhenius equation and thermal desorption spectroscopy (Pigram et al., 1994).

The above methods are generally successful in predicting the adsorption of volatile organic compounds (VOCs) onto activated carbon under specific conditions. However, the thermodynamic method considers adsorption as an equilibrium process. The empirical method lacks a theoretical rigor. In this study, based on the basic dynamical reaction (BDR) theory, a thermodynamic model, called BDR model, involving non-linear driving force was used to predict the kinetics of the adsorption of three VOCs onto activated carbon. Important kinetic parameters, such as adsorption rate constant and activation energy were determined to obtain the adsorption isotherm and evaluate the adsorption behavior under different operational conditions. This non-linear reaction kinetic approach can also be used to predict the adsorption rate of VOCs in column operations.

\section{Experimental method}

\subsection{Materials}

Benzene $\left(\mathrm{C}_{6} \mathrm{H}_{6}\right)$, carbon tetrachloride $\left(\mathrm{CCl}_{4}\right)$ and trichloromethane $\left(\mathrm{CHCl}_{3}\right)$ were the adsorbent VOCs studied. The activated carbon was of pellet form with a diameter of $3 \mathrm{~mm}$ and a density of $880 \mathrm{~kg} / \mathrm{m}^{3}$ (Sorbonorit 3, Norit, the Netherlands). The activated carbon was ground first then sieved to a size fraction from 0.35 to $0.50 \mathrm{~mm}$ (or 35 to $45 \mathrm{mesh}$ ) and heated to $573 \mathrm{~K}$ in a $\mathrm{N}_{2}$ atmosphere (purity $99.99 \%$ ) over $24 \mathrm{~h}$ to remove any adsorbed gas. The treated activated carbon was stored in a $\mathrm{N}_{2}$-filling chamber $(300 \mathrm{~K})$ before experiments.

VOC was generated by passing a stream of water and hydrocarbon-free $\mathrm{N}_{2}$ gas over a series of diffusion tubes containing the pure liquid of interest. The VOC concentrations were controlled by the number of diffusion tubes and temperature as well as the carrier gas flow rate $(1.2 \mathrm{l} / \mathrm{min}$ at $303 \mathrm{~K}$ by a mass flow meter, Instrument Inc., Sierra). The temperature of the VOC vapor was controlled by a thermostat (283-363 K) before entering the reaction column (Fig. 1). The concentrations of $\mathrm{C}_{6} \mathrm{H}_{6}, \mathrm{CCl}_{4}$ and $\mathrm{CHCl}_{3}$ studied were in the concentration range of $8-150,6-300$ and $10-220 \mathrm{mmol} / \mathrm{m}^{3}$, respectively.

\subsection{Adsorption and desorption in activated carbon bed}

For VOC adsorption experiments, about 600-2000 $\mathrm{mg}$ of treated activated carbon was packed in a small glass column (height $=9-30 \mathrm{~mm}$ and cross-section area $=1.76 \mathrm{~cm}^{2}$ ). The column temperature was maintained at the range from 283 to $363 \mathrm{~K}$ for $3 \mathrm{~h}$ before testing. During adsorption experiments the outlet gas was continuously monitored for VOC with a portable photoionization air monitor (Perkinelmer, Photovac Model 2020). The measurements were calibrated by gas chromatography (HP 5890A; column: Supel Co., VOCOL $^{\mathrm{TM}}, \# 9354-04 \mathrm{~A}$ ) with a flame ionization detector. After the termination of the adsorption experiment, the inlet gas was changed to the $\mathrm{N}_{2}$ carried gas and the outlet gas was continuously monitored with the same portable photoionization air monitor for obtaining desorption data. The detection limits of $\mathrm{C}_{6} \mathrm{H}_{6}, \mathrm{CCl}_{4}$ and $\mathrm{CHCl}_{3}$ were $4.0 \times 10^{-6}, 1.2 \times 10^{-6}$ and $1.2 \times 10^{-6} \mathrm{mmol} / \mathrm{m}^{3}$, respectively.

\section{Mathematical model}

The concentration change of the contaminant in the column can be described by the following equation: 


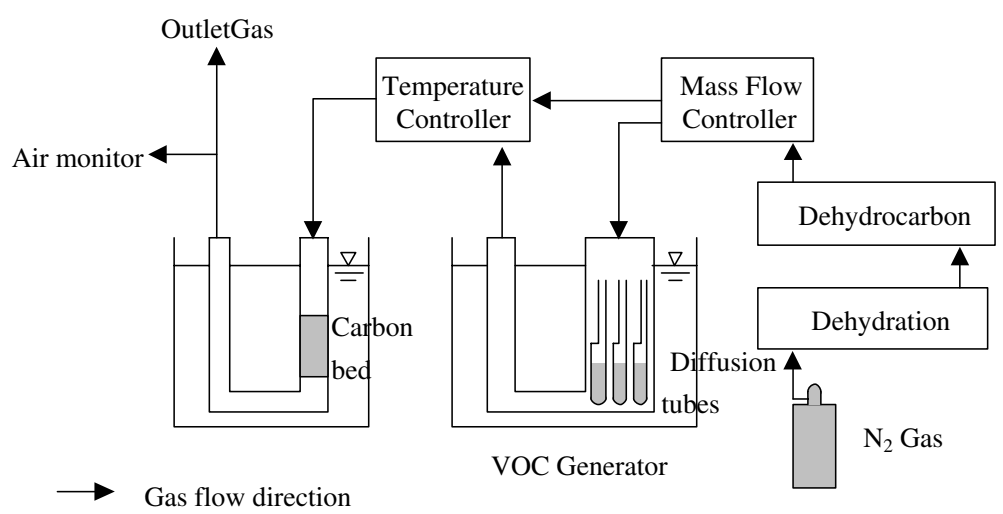

Fig. 1. Experimental apparatus.

$\frac{\partial C}{\partial t}-D_{\mathrm{L}} \frac{\partial^{2} C}{\partial^{2} L}+U \frac{\partial C}{\partial L}+\frac{1-\varepsilon}{\varepsilon} \rho \frac{\partial q}{\partial t}=0$

where $D_{\mathrm{L}}, C, L, U, \varepsilon, \rho$, and $q$ are the dispersion coefficient $\left(\mathrm{m}^{2} / \mathrm{s}\right)$, the concentration of VOC in the gas phase $\left(\mathrm{mol} / \mathrm{m}^{3}\right)$, the length of activated carbon bed $(\mathrm{m})$, the gas velocity $(\mathrm{m} / \mathrm{s})$, the bed void fraction, the density of activated carbon $\left(\mathrm{g} / \mathrm{m}^{3}\right)$, and the adsorption capacity $(\mathrm{g} / \mathrm{g})$, respectively. By assuming the process as a non-equilibrium surface reaction and since the column is relatively short, the diffusion term can be negligible. Base on thermodynamic consideration, the forward reaction rate $\left(R_{\mathrm{a}}, 1 / \mathrm{s}\right)$ is a function of the adsorbent concentration and free surface site ratio $(1-\theta)$, i.e.,

$R_{\mathrm{a}}=k_{\mathrm{a}}(1-\theta) C$

where $k_{\mathrm{a}}$ is the adsorption rate constant, $\mathrm{m}^{3} /(\mathrm{s} \mathrm{mol})$ and $\theta$ is the surface coverage, equal to $q / q_{0}$, where $q_{0}$ is the maximum adsorptive capacity at the monolayer level $(\mathrm{g} / \mathrm{g})$. Likewise, the backward reaction rate $\left(R_{\mathrm{d}}\right)$ is closely related to $\theta$ :

$R_{\mathrm{d}}=k_{\mathrm{d}} \theta$

where $k_{\mathrm{d}}$ is the desorption rate constant $(1 / \mathrm{s})$. The net reaction rate $(R, 1 / \mathrm{s})$ is equal to the subtraction of $R_{\mathrm{d}}$ from $R_{\mathrm{a}}$ :

$R=\frac{\partial \theta}{\partial t}=k_{\mathrm{a}}(1-\theta) C-k_{\mathrm{d}} \theta$

In Eq. (1), $(1-\varepsilon) / \varepsilon$ means the ratio of solid phase volume to gas phase volume. In a packed activated carbon bed, the solid phase volume equal to $W / \rho$ and the gas phase volume equal to $(L A-W / \rho)$, where $W$ is the weight of activated carbon $(\mathrm{g}), A$ the cross-sectional area of the adsorption bed $\left(\mathrm{m}^{2}\right)$. Eq. (1) can be rewritten as:

$\frac{\partial C}{\partial t}=-U \frac{\partial C}{\partial L}-\frac{\partial \theta}{\partial t} S$ where $S\left(\mathrm{~g} / \mathrm{m}^{3}\right)$ is a conversion factor between solid and gas phase, which can be expressed by the following relation:

$S=\frac{q_{0} W}{L A-W / \rho}$

It is known that the flow rate, $Q\left(\mathrm{~m}^{3} / \mathrm{s}\right)$, has the following expression:

$Q=U A\left(1-\frac{\frac{W}{\rho}}{L A}\right)$

It is assumed that the activated carbon bed can be treated as an entity consisting $n$-series $(n=50)$ of constant volume units, i.e., the physicochemical conditions within each unit are identical, and that the adsorption/ desorption process follows the Langmuir model. Let $\Delta t$ (s) and $\Delta V\left(\mathrm{~m}^{3}\right)$ be the reaction time and the gas volume in each unit. At the $i$ th unit and experimental time, $t$, the concentration change in the solid phase and the gas phase can be determined by a finite difference method:

In the solid phase from Eq. (4), one has

$\theta_{i}^{t+\Delta t}=\theta_{i}^{t}+\left[k_{\mathrm{a}}\left(1-\theta_{i}^{t}\right) C_{i}^{t}-k_{\mathrm{d}} \theta_{i}^{t}\right] \Delta t$

In the gas phase from Eq. (5), it yields

$C_{i}^{t+\Delta t}=C_{i}^{t}+\frac{Q \Delta t}{\Delta V}\left(C_{i}^{t}-C_{i-1}^{t}\right)+\left[-k_{\mathrm{a}}\left(1-\theta_{i}^{t}\right) C_{i}^{t}+k_{\mathrm{d}} \theta_{i}^{t}\right] S \Delta t$

Accordingly, $\Delta V$ can be expressed by the following equation:

$\Delta V=\frac{L A-\frac{W}{\rho}}{n}$

Fig. 2 shows the conceptual presentation of the modeling approach. 


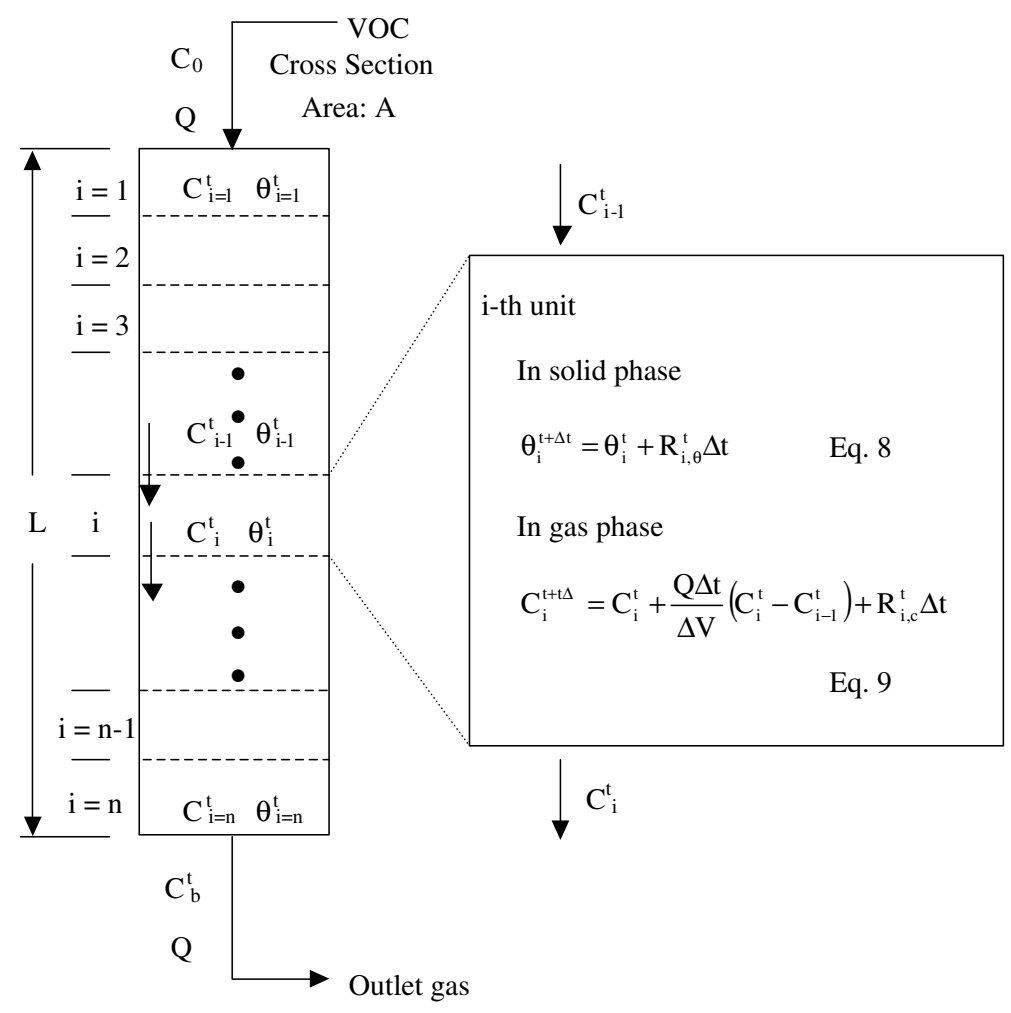

Fig. 2. Conceptual presentation of the modeling approach.

By definition, the equilibrium adsorption mass, $W_{\mathrm{e}}$, can be calculated by the following equation:

$W_{\mathrm{e}}=\int_{0}^{\infty}\left(C_{0}-C_{\mathrm{b}}\right) Q \mathrm{~d} t$

where $C_{0}$ and $C_{\mathrm{b}}$ are the inlet and outlet organic vapor concentrations, respectively, and $W_{\mathrm{e}}$ is the equilibrium adsorption mass. From $W_{\mathrm{e}}$, it is possible to calculate the parameters of Langmuir isotherm, i.e., $q_{0}$ and $K_{\mathrm{L}}$. In this study a SYSTAT software package was used.

To perform the numerical modeling computation, a series of known variables $\left(\rho, A, C_{0}, W, L, Q\right.$ and $\left.T\right)$ and estimated parameters $\left(k_{\mathrm{a}}\right.$ and $k_{\mathrm{d}}$ ) were input into Eqs. (8) and (9) followed by iteration to obtain the breakthrough curves, and the reaction rates $\left(R_{\mathrm{a}}, R_{\mathrm{d}}\right.$, and $\left.R\right)$ were well known, too. The best fit of $k_{\mathrm{a}}$ and $k_{\mathrm{d}}$ was verified by evaluating the root mean square error, $\delta$ :

$\delta=\frac{1}{C_{0}} \sqrt{\frac{1}{N} \sum_{n=1}^{N}\left(C_{\mathrm{b}}-C^{\prime}\right)^{2}}$

where $C_{\mathrm{b}}$ and $C^{\prime}$ are the observed and calculated concentrations at breakthrough, respectively, and $N$ is the number measured in each test.

\section{Results and discussion}

4.1. Determination reaction rate constant and activation energy $\left(k_{a}, k_{d}, E_{a}\right.$, and $\left.E_{d}\right)$

Table 2 shows the results of column operation under various experimental conditions. Note that the retention time, $\tau$, is defined as $(L A-W / \rho) / Q$. Clearly, the BDR model can reasonably predict the outlet VOC concentration $(\delta=0.01-0.07)$. As would be expected, both adsorption and desorption rates increased with temperature. For example, the desorption rate constant of $\mathrm{CHCl}_{3}$ increased from $4.7 \times 10^{-4}$ to $1.6 \times 10^{-1} 1 / \mathrm{s}$ as the temperature increased from 283 to $363 \mathrm{~K}$ with the corresponding adsorption rate constant $1.5 \times 10^{-1}$ and 1.05 $\mathrm{m}^{3} /(\mathrm{smol})$. It is also noted that the increase in the desorption rate constant was greater than that of the adsorption rate constant. Consequently, the equilibrium constant $\left(K=k_{\mathrm{a}} / k_{\mathrm{d}}\right)$ decreased by two orders of magnitude $\left(319-6.5 \mathrm{~m}^{3} / \mathrm{mol}\right)$, indicating the adsorption being an exothermic process $(\Delta H<0)$. Results also show that $\mathrm{CCl}_{4}$ exhibited the highest equilibrium adsorption constant and $\mathrm{C}_{6} \mathrm{H}_{6}$ possessed the lowest.

Table 3 presents the equilibrium constants calculated from the Langmuir isotherm, LDF and BDR models which indicate that there is no significant difference in 
Table 2

Adsorption conditions, parameters and statistics

\begin{tabular}{|c|c|c|c|c|c|c|c|c|}
\hline \multirow{2}{*}{$\begin{array}{l}\text { VOC } \\
\mathrm{C}_{6} \mathrm{H}_{6}\end{array}$} & \multicolumn{2}{|c|}{ Adsorption conditions and parameters } & \multirow{2}{*}{$\begin{array}{l}\text { Unit } \\
\mathrm{g}\end{array}$} & \multirow{2}{*}{$\begin{array}{l}\text { Run } 1 \\
283 \mathrm{~K} \\
2.001\end{array}$} & \multirow{2}{*}{$\begin{array}{l}\text { Run } 2 \\
303 \mathrm{~K} \\
2.005\end{array}$} & \multirow{2}{*}{$\begin{array}{l}\text { Run } 3 \\
323 \mathrm{~K} \\
2.001\end{array}$} & \multirow{2}{*}{$\begin{array}{l}\text { Run } 4 \\
343 \mathrm{~K} \\
2.002\end{array}$} & \multirow{2}{*}{$\begin{array}{l}\text { Run } 5 \\
363 \mathrm{~K} \\
2.001\end{array}$} \\
\hline & Reaction conditions & Weight of carbon, $W$ & & & & & & \\
\hline & & Length of carbon bed, $L$ & $\mathrm{~cm}$ & 3 & 3.1 & 3 & 3 & 3 \\
\hline & & Influent concentration, $C_{0}$ & $\mathrm{mmol} / \mathrm{m}^{3}$ & 116 & 132 & 108 & 103 & 88 \\
\hline & & Saturation concentration, $C_{\mathrm{sat}}$ & $\mathrm{mol} / \mathrm{m}^{3}$ & 2.6 & 6.3 & 13.5 & 25.8 & 45.1 \\
\hline & & Flow rate, $Q$ & $1 / \mathrm{min}$ & 1.14 & 1.2 & 1.3 & 1.38 & 1.46 \\
\hline & & Retention time, $\tau$ & $\mathrm{s}$ & $1.60 \times 10^{-1}$ & $1.59 \times 10^{-1}$ & $1.41 \times 10^{-1}$ & $1.33 \times 10^{-1}$ & $1.25 \times 10^{-1}$ \\
\hline & Reaction parameters & Adsorption rate constant, $k_{\mathrm{a}}$ & $\mathrm{m}^{3} /(\mathrm{s} \mathrm{mol})$ & $1.3 \times 10^{-2}$ & $1.6 \times 10^{-2}$ & $1.9 \times 10^{-2}$ & $4.0 \times 10^{-2}$ & $6.0 \times 10^{-2}$ \\
\hline & & Desorption rate constant, $k_{\mathrm{d}}$ & $1 / \mathrm{s}$ & $1.0 \times 10^{-4}$ & $4.4 \times 10^{-4}$ & $1.6 \times 10^{-3}$ & $5.0 \times 10^{-3}$ & $1.1 \times 10^{-2}$ \\
\hline & & Equilibrium constant, $K=k_{\mathrm{a}} / k_{\mathrm{d}}$ & $\mathrm{m}^{3} / \mathrm{mol}$ & 130 & 37 & 12 & 8.0 & 5.4 \\
\hline & & Measured equilibrium constant, $K_{\mathrm{L}}$ & $\mathrm{m}^{3} / \mathrm{mol}$ & 112 & 40 & 23 & 11 & 6.3 \\
\hline & Statistics & Measured number in each test, $N$ & - & 27 & 29 & 41 & 32 & 26 \\
\hline & & Root mean square error, $\delta$ & - & 0.02 & 0.03 & 0.03 & 0.05 & 0.04 \\
\hline & & Arrhenius equations & $\begin{array}{l}- \\
- \\
-\end{array}$ & \multicolumn{5}{|c|}{$\begin{array}{l}\ln \left(k_{\mathrm{a}}\right)=-2000 / T+2.6, R^{2}=0.90, E_{\mathrm{a}}=4.0 \mathrm{kcal} / \mathrm{mol}, a=13.0 \mathrm{~m}^{3} /(\mathrm{s} \mathrm{mol}) \\
\ln \left(k_{\mathrm{d}}\right)=-6100 / T+13, R^{2}=0.99, E_{\mathrm{d}}=12.2 \mathrm{kcal} / \mathrm{mol}, a=2.6 \times 10^{5} 1 / \mathrm{s} \\
\ln (K)=4100 / T-9.9, R^{2}=0.96, E=-8.2 \mathrm{kcal} / \mathrm{mol}, a=1.9 \times 10^{4} \mathrm{~m}^{3} / \mathrm{mol}\end{array}$} \\
\hline \multirow[t]{13}{*}{$\mathrm{CCl}_{4}$} & Reaction conditions & Weight of carbon, $W$ & $\mathrm{~g}$ & 0.600 & 0.600 & 0.600 & 0.600 & 0.600 \\
\hline & & Length of carbon bed, $L$ & $\mathrm{~cm}$ & 0.9 & 0.9 & 0.9 & 0.9 & 0.9 \\
\hline & & Influent concentration, $C_{0}$ & $\mathrm{mmol} / \mathrm{m}^{3}$ & 26.8 & 23.7 & 22.5 & 22.2 & 20.6 \\
\hline & & Saturation concentration, $C_{\mathrm{sat}}$ & $\mathrm{mol} / \mathrm{m}^{3}$ & 3.2 & 7.5 & 15.5 & 28.9 & 49.5 \\
\hline & & Flow rate, $Q$ & $1 / \mathrm{min}$ & 1.15 & 1.21 & 1.31 & 1.39 & 1.47 \\
\hline & & Retention time, $\tau$ & $\mathrm{s}$ & $4.70 \times 10^{-2}$ & $4.46 \times 10^{-2}$ & $4.14 \times 10^{-2}$ & $3.89 \times 10^{-2}$ & $3.68 \times 10^{-2}$ \\
\hline & Reaction parameters & Adsorption rate constant, $k_{\mathrm{a}}$ & $\mathrm{m}^{3} /(\mathrm{s} \mathrm{mol})$ & $7.5 \times 10^{-2}$ & $1.0 \times 10^{-1}$ & $1.5 \times 10^{-1}$ & $2.0 \times 10^{-1}$ & $6.0 \times 10^{-1}$ \\
\hline & & Desorption rate constant, $k_{\mathrm{d}}$ & $1 / \mathrm{s}$ & $4.0 \times 10^{-5}$ & $1.1 \times 10^{-3}$ & $3.0 \times 10^{-3}$ & $4.8 \times 10^{-3}$ & $3.1 \times 10^{-2}$ \\
\hline & & Equilibrium constant, $K=k_{\mathrm{a}} / k_{\mathrm{d}}$ & $\mathrm{m}^{3} / \mathrm{mol}$ & 1900 & 90 & 50 & 42 & 19 \\
\hline & & Measured equilibrium constant, $K_{\mathrm{L}}$ & $\mathrm{m}^{3} / \mathrm{mol}$ & 2200 & 100 & 78 & 40 & 17 \\
\hline & Statistics & Measured number in each test, $N$ & - & 41 & 29 & 24 & 22 & 19 \\
\hline & & Root mean square error, $\delta$ & - & 0.04 & 0.07 & 0.02 & 0.02 & 0.03 \\
\hline & & Arrhenius equations & $\begin{array}{l}- \\
- \\
-\end{array}$ & \multicolumn{5}{|c|}{$\begin{array}{l}\ln \left(k_{\mathrm{a}}\right)=-2400 / T+5.8, R^{2}=0.87, E_{\mathrm{a}}=4.8 \mathrm{kcal} / \mathrm{mol}, a=340 \mathrm{~m}^{3} /(\mathrm{s} \mathrm{mol}) \\
\ln \left(k_{\mathrm{d}}\right)=-7700 / T+18, R^{2}=0.93, E_{\mathrm{d}}=15.3 \mathrm{kcal} / \mathrm{mol}, a=4.6 \times 10^{7} 1 / \mathrm{s} \\
\ln (K)=5200 / T-12, R^{2}=0.83, E=-10.4 \mathrm{kcal} / \mathrm{mol}, a=1.4 \times 10^{5} \mathrm{~m}^{3} / \mathrm{mol}\end{array}$} \\
\hline \multirow[t]{4}{*}{$\mathrm{CHCl}_{3}$} & Reaction conditions & Weight of carbon, $W$ & g & 0.600 & 0.600 & 0.600 & 0.600 & 0.600 \\
\hline & & Length of carbon bed, $L$ & $\mathrm{~cm}$ & 0.9 & 0.9 & 0.9 & 0.9 & 0.9 \\
\hline & & Influent concentration, $C_{0}$ & $\mathrm{mmol} / \mathrm{m}^{3}$ & 32.6 & 83.3 & 71.8 & 69.1 & 64.9 \\
\hline & & Saturation concentration, $C_{\mathrm{sat}}$ & $\mathrm{mol} / \mathrm{m}^{3}$ & 5.64 & 12.84 & 25.81 & 46.97 & 78.93 \\
\hline
\end{tabular}




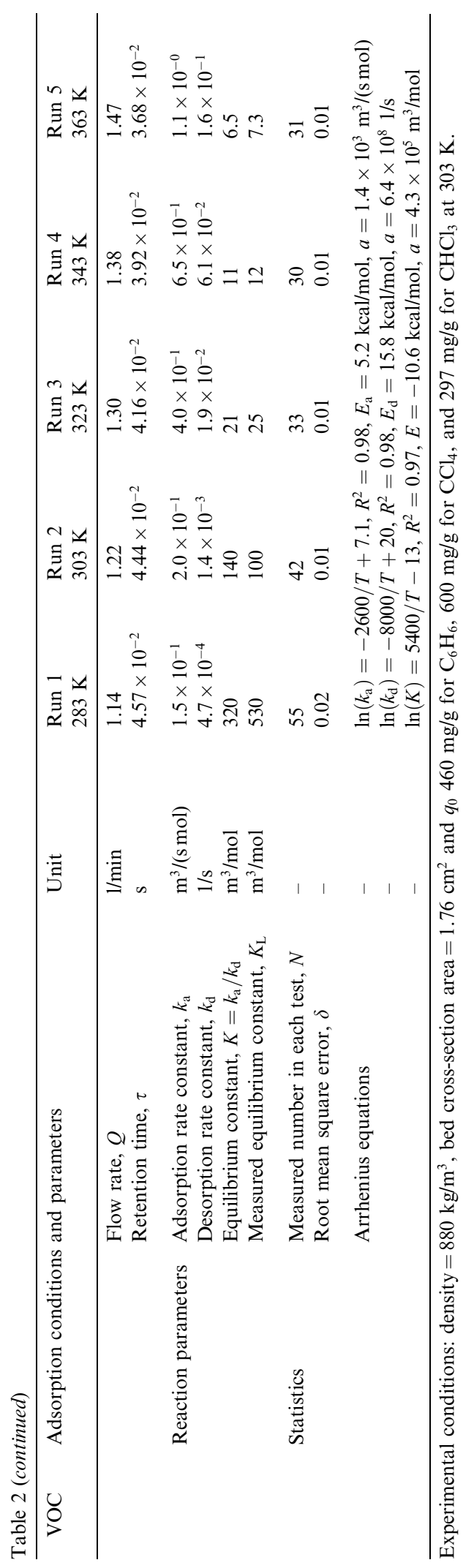

Table 3

Comparison of equilibrium constants from different models

\begin{tabular}{llccccc}
\hline VOC & Model & \multicolumn{7}{l}{ Temperature $(\mathrm{K})$} \\
\cline { 2 - 6 } & & 283 & 303 & 323 & 343 & 363 \\
\hline $\mathrm{C}_{6} \mathrm{H}_{6}$ & Langmuir & 112 & 40 & 23 & 11 & 6.3 \\
& isotherm $\left(K_{\mathrm{L}}\right)$ & & & & & \\
& LDF $\left(K_{\mathrm{LDF}}\right)$ & 150 & 37 & 12 & 8.2 & 5.5 \\
& BDR (this & 130 & 37 & 12 & 8.0 & 5.4 \\
& study) $\left(k_{\mathrm{a}} / k_{\mathrm{d}}\right)$ & & & & & \\
$\mathrm{CCl}_{4}$ & Langmuir & 2200 & 100 & 78 & 40 & 17 \\
& isotherm $\left(K_{\mathrm{L}}\right)$ & & & & & \\
& LDF $\left(K_{\mathrm{LDF}}\right)$ & 2000 & 95 & 50 & 42 & 19 \\
& BDR (this & 1900 & 90 & 50 & 42 & 19 \\
& study) $\left(k_{\mathrm{a}} / k_{\mathrm{d}}\right)$ & & & & & \\
$\mathrm{CHCl}_{3}$ & Langmuir & 530 & 100 & 25 & 12 & 7.3 \\
& isotherm $\left(K_{\mathrm{L}}\right)$ & & & & & \\
& LDF $\left(K_{\mathrm{LDF}}\right)$ & 450 & 170 & 22 & 11 & 6.5 \\
& BDR (this & 320 & 140 & 21 & 11 & 6.5 \\
& study) $\left(k_{\mathrm{a}} / k_{\mathrm{d}}\right)$ & & & & & \\
\hline
\end{tabular}

${ }^{\mathrm{a}}$ LDF with Langmuir isotherm.

those equilibrium constants. In general, the equilibrium constants calculated from the BDR model were located between those calculated from Langmuir isotherm and LDF model with the exception of $\mathrm{CCl}_{4}$. The equilibrium constants of $\mathrm{CCl}_{4}$ were higher than that of $\mathrm{C}_{6} \mathrm{H}_{6}$ and $\mathrm{CHCl}_{3}$ which implied that $\mathrm{CCl}_{4}$ was a stronger adsorbate than $\mathrm{C}_{6} \mathrm{H}_{6}$ and $\mathrm{CHCl}_{3}$.

Based on the Arrhenius equation, the activation energy and frequency coefficient can be calculated from the corresponding models and shown in Table 2. Fig. 3 shows the correlation of the reaction constants $(\ln k)$ and the temperature $(1 / T)$, in which the determination of the relevant activation energy associated with the selected VOCs were revealed. For instance, the $E_{\mathrm{a}}$ of $\mathrm{C}_{6} \mathrm{H}_{6}, \mathrm{CCl}_{4}$ and $\mathrm{CHCl}_{3}$ were $4.0,4.8$ and $5.1 \mathrm{kcal} / \mathrm{mol}$, respectively; and the respective $E_{\mathrm{d}}$ values were $12.2,15.3$ and 15.8 $\mathrm{kcal} / \mathrm{mol}$. For the Langmuir model, the $a_{\mathrm{a}}$ of $\mathrm{C}_{6} \mathrm{H}_{6}, \mathrm{CCl}_{4}$ and $\mathrm{CHCl}_{3}$ were 13,340 and $1240 \mathrm{~m}^{3} /(\mathrm{s} \mathrm{mol})$, respectively; the respective $a_{\mathrm{d}}$ values were $2.6 \times 10^{5}, 4.6 \times 10^{7}$ and $6.4 \times 10^{8} 1 / \mathrm{s}$. Consequently, the heat of adsorption of $\mathrm{C}_{6} \mathrm{H}_{6}, \mathrm{CCl}_{4}$ and $\mathrm{CHCl}_{3}$ can be determined; the values are $-8.2,-10.4$ and $-10.7 \mathrm{kcal} / \mathrm{mol}$, respectively, and these values are similar to those reported by Chiang et al. (2001). Summary, $\mathrm{CHCl}_{3}$ has a larger adsorption rate constant, desorption rate constant, adsorption activation energy, and desorption activation energy but a lower heat of adsorption and adsorption capacity than that of $\mathrm{C}_{6} \mathrm{H}_{6}$ and $\mathrm{CCl}_{4}$.

Table 4 presents the model (LDF and BDR) comparison from the aspects of principle and applications. In principle, LDF assumes the adsorption rate should be linearly proportional to a driving force which is determined by the difference between the surface concentra- 


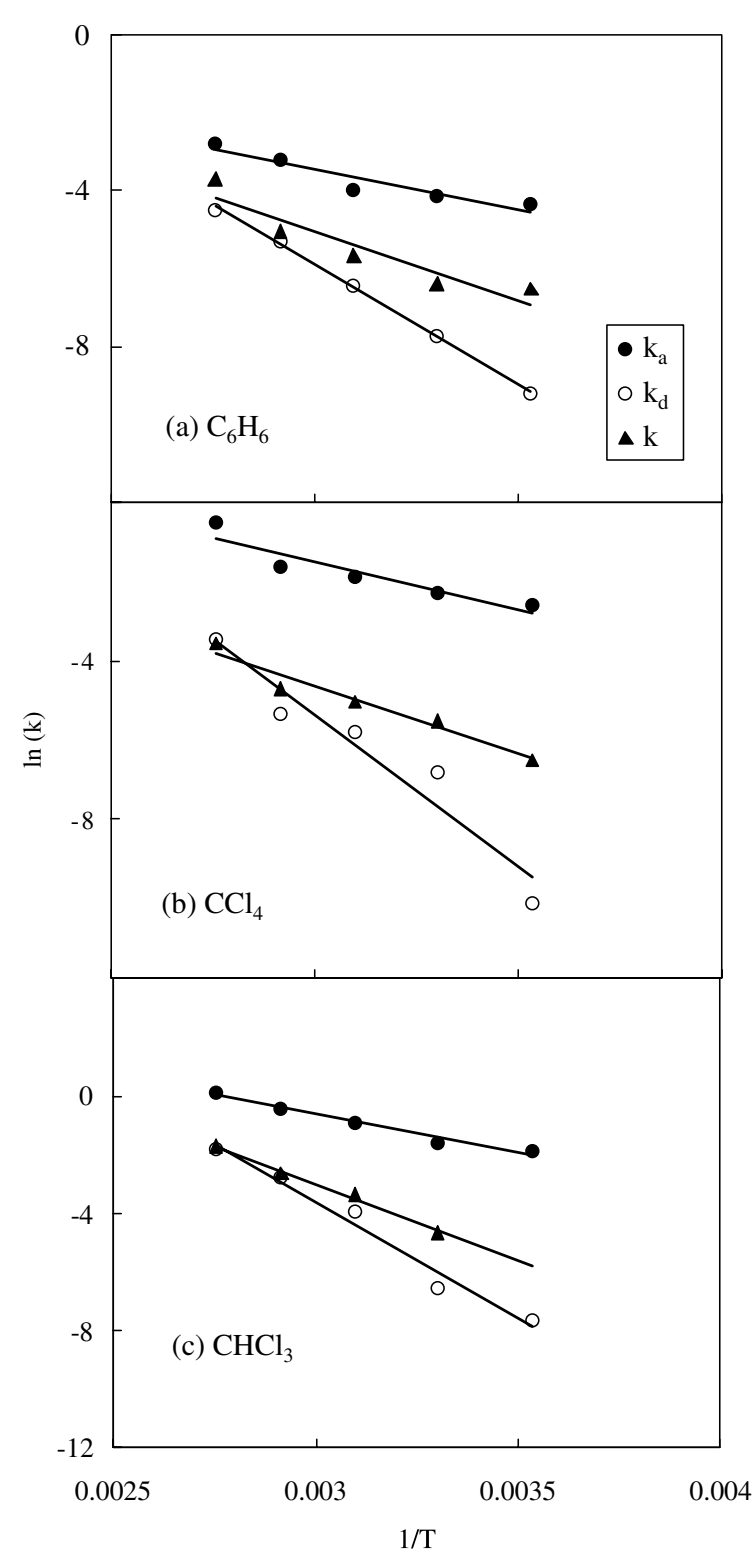

Fig. 3. Relationship between rate constants $\left(k_{\mathrm{a}}, k_{\mathrm{d}}\right.$, and $\left.k\right)$ and temperature.

tion $\left(q^{*}\right)$ and the average adsorbed-phase concentration (q) (Gkueckauf, 1955). The surface concentration can be expressed either by Langmuir or Freundlich isotherms. The BDR model is based on the basic dynamical reaction theory and assumes the adsorption and desorption rate should be a function of adsorbent concentration and free surface site ratio $(1-\theta)$ and desorption of coverage ratio $(\theta)$, respectively, which are consistent with the Langmuir isotherm. In addition, the LDF is a lumped-parameter (adsorbed-phase transfer coefficient, $k$ ) model for particle adsorption (Malek and Farooq, 1997) which could be applicable to the non-isothermal, multicomponent mixture dynamic-column adsorption process. The BDR model used adsorption reaction constant $\left(k_{\mathrm{a}}\right)$ and desorption reaction constant $\left(k_{\mathrm{d}}\right)$ to describe the adsorption process.

\subsection{Effect of temperature and concentration}

In this study, both $\mathrm{C}_{6} \mathrm{H}_{6}$ and $\mathrm{CCl}_{4}$ are non-polar molecules with a zero dipole moment, whereas $\mathrm{CHCl}_{3}$ is a polar molecule with a dipole moment of $1.1 \mathrm{D}$. Breysse et al. (1987) studied the adsorption ability of three dichlorobenzene isomers on activated carbon and reported that dipole moment does not have significant effects on the adsorption of VOC for $D<2.5$. Fig. 4 shows the adsorption capacity as a function of "relative concentration" where $C_{\mathrm{sat}}$ is the saturation concentration. For ideal gas, $C_{0} / C_{\text {sat }}$ is identical to $P_{0} / P_{\text {sat }}$ at a given temperature, where $P_{0}$ is inlet partial pressure (atm) and $P_{\text {sat }}$ is the saturation pressure $(\mathrm{atm})$. As expected, the adsorption capacity increased with the VOC concentration and/or partial pressure. The Langmuir model was chosen in subsequent numerical model analysis of the adsorption/desorption process. Table 2 shows the Langmuir constant $\left(K_{\mathrm{L}}\right)$. At $303 \mathrm{~K}$, the adsorptive capacity $\left(q_{0}\right)$ of $\mathrm{C}_{6} \mathrm{H}_{6}, \mathrm{CCl}_{4}$ and $\mathrm{CHCl}_{3}$ are 460,600 and $297 \mathrm{mg} / \mathrm{g}$, respectively, and the $K_{\mathrm{L}}$ of $\mathrm{C}_{6} \mathrm{H}_{6}, \mathrm{CCl}_{4}$ and $\mathrm{CHCl}_{3}$ are 40,100 and $100 \mathrm{~m}^{3} / \mathrm{mol}$, respectively. The values of $q_{0}$ and $K_{\mathrm{L}}$ are in the same order of magnitude as those reported by Vahdat (1997). The results also indicate that $\mathrm{CCl}_{4}$ has high adsorptive capacity and adsorption constant, which implies that $\mathrm{CCl}_{4}$ is a stronger adsorbate towards activated carbon than $\mathrm{C}_{6} \mathrm{H}_{6}$ and $\mathrm{CHCl}_{3}$.

Fig. 5 presents the relationship between the model fitted equilibrium constant, $k_{\mathrm{a}} / k_{\mathrm{d}}$, and measured constant, $K_{\mathrm{L}}$, as reported by Vahdat (1997), Chiang et al. (2001) and this study. The plot indicates a linear correlation between $K_{\mathrm{L}}$ and $k_{\mathrm{a}} / k_{\mathrm{d}}$. The dimensionless plots in Fig. 6 show the predicted breakthrough curves as a function of temperature (the reaction conditions are shown in Table 2). The results indicated that, at higher temperatures, an early breakthrough occurs due to reduced adsorption capacity (lower equilibrium constants). Furthermore, the breakthrough curves were steeper at higher temperatures due in part to the effects of $k_{\mathrm{a}}$ and $k_{\mathrm{d}}$.

In this study, the adsorption and desorption reaction constants determined at different temperatures (from 283 to $363 \mathrm{~K}$ ) were used to predict the desorption concentration changes at 343 and $363 \mathrm{~K}$. The desorption efficiency, i.e., total adsorption weight/total desorption weight, ranged from $85 \%$ to $101 \%$. Results (Fig. 7) show that the numerical model could well predict the desorption process for $\mathrm{CHCl}_{3}$. For the other two VOCs, 
Table 4

Comparison between LDF and BDR model

\begin{tabular}{|c|c|c|c|}
\hline Model & & $\mathrm{LDF}$ & BDR \\
\hline \multirow[t]{3}{*}{ Principle } & Similarities & $\frac{\partial C}{\partial t}-D_{\mathrm{L}} \frac{\partial^{2} C}{\partial^{2} L}+U \frac{\partial C}{\partial L}+\frac{1-\varepsilon}{\varepsilon} \rho \frac{\partial q}{\partial t}=0$ & \\
\hline & Dissimilarities & $\frac{\partial q}{\partial t}=k\left(q^{*}-q\right)$ & $\frac{\partial \theta}{\partial t}=k_{\mathrm{a}}(1-\theta) C-k_{\mathrm{d}} \theta$ \\
\hline & & $\begin{array}{l}\text { The uptake is linearly proportional to a driving } \\
\text { force, defined as the difference between the } \\
\text { surface concentration }\left(q^{*}\right) \text { and the average } \\
\text { adsorbed-phase concentration }(q)\end{array}$ & $\begin{array}{l}\text { Based on the Langmuir hypothesis, the ad- } \\
\text { sorption rate is a function of adsorbent con- } \\
\text { centration }(C) \text { and free surface site ratio } \\
(1-\theta) \text {, and desorption rate is a function of } \\
\text { coverage ratio }(\theta)\end{array}$ \\
\hline \multirow[t]{2}{*}{ Application } & Similarities & $\begin{array}{l}\text { 1. Applied at non-isothermal process } \\
\text { 2. Applied at multi-component mixture system }\end{array}$ & \\
\hline & Dissimilarities & $\begin{array}{l}\text { 1. Associated with several isotherms, such as } \\
\text { Langmuir and Freundlich isotherm } \\
\text { 2. Only net reaction rate was known } \\
\text { 3. Applied at both particle and } \\
\text { dynamic-column adsorption } \\
\text { 4. Usually applied at adsorption process }\end{array}$ & $\begin{array}{l}\text { 1. Direct associated with Langmuir isotherm } \\
\text { 2. Both adsorption and desorption reaction } \\
\text { rates were known } \\
\text { 3. Applied at dynamic-column adsorption } \\
\text { 4. Applied at both adsorption and desorption } \\
\text { process }\end{array}$ \\
\hline
\end{tabular}

the results show that the measured outlet concentrations were lower than the predicted values. It is also observed that the $C_{\text {out }} / C_{0}$ values at higher temperatures decrease more rapidly than that those at lower temperatures.

\subsection{Adsorption and desorption rate}

In the present study, the numerical model provides the adsorption and the desorption rate constants, and these parameters can be used to predict the desorption process. Further, the numerical model provides the change in both the adsorption and the desorption rates as a function of temperature and time (e.g., $\mathrm{CCl}_{4}$ from 283 to $363 \mathrm{~K}$ in Fig. 8). The pattern in Fig. 8 plots is of course affected by temperature. At higher adsorption temperatures (323, 343 and $363 \mathrm{~K}$; Fig. 8 top), the adsorption rate appears to be slightly higher than the desorption rate. Both the adsorption reaction rate, $R_{\mathrm{a}}$, and the desorption reaction rate, $R_{\mathrm{d}}$, increase with time and eventually reach equilibrium. The net reaction rate, $R$, reaches a maximum value before approaching zero. At low adsorption temperature (283 and $303 \mathrm{~K}$; Fig. 8 bottom), the adsorption rate is much higher than the desorption rate. The desorption and net reaction rates exhibit the same trend with those at higher adsorption temperatures. On the other hand, the adsorption reaction rates show a different trend. It reached a maximum value and then declined to the level equivalent to the desorption rate. Since the adsorption rate is equal $k_{\mathrm{a}}(1-\theta) C$, the $1-\theta$ value at lower temperatures changes appreciably than that at higher temperatures. The increase of $C$ (from 0 to $C_{0}$ ) and the decrease of $1-\theta$ (from 1 to $1-\theta_{\mathrm{e}}$ ) cause the adsorption rate exhibiting a maximum value and then gradually decreases.

The case of $\mathrm{CCl}_{4}$ show the adsorption reaction rates, the desorption reaction rates and net reaction rates are the function of temperatures, and when adsorption process approaches equilibrium (i.e., $R_{\mathrm{a}}=R_{\mathrm{d}}$ ), the adsorption rate (or desorption rate) at high reaction temperature is higher than that at low temperatures. For the other two VOCs, the plots show the same trend as in the case of $\mathrm{CCl}_{4}$.

Fig. 9 presents the changes of adsorption and desorption rates of $\mathrm{CCl}_{4}$ during the desorption process at two temperatures (343 and $363 \mathrm{~K}$ ). The results show that the desorption rates are slightly higher than the adsorption rates. At the beginning of desorption experiments, both the adsorption and desorption rates at the higher temperature were higher than that at the lower temperature; after that, the adsorption and desorption rates at the higher temperature decreased rapidly than that at the lower temperature, and the net reaction rate indicates a $\max$ value and a right-trail curve.

In this study, the experimental data showed that the adsorption process is an exothermic process $(\Delta H<0)$; a higher temperature will decrease the adsorption capacity $\left(q / q_{0}\right)$. As expected, high temperature will increase both the adsorption and desorption reaction rate constants, high rate constants will cause high reaction rate, and high reaction rate will cause the reaction easy reach the equilibrium state and reduce the reaction time. 


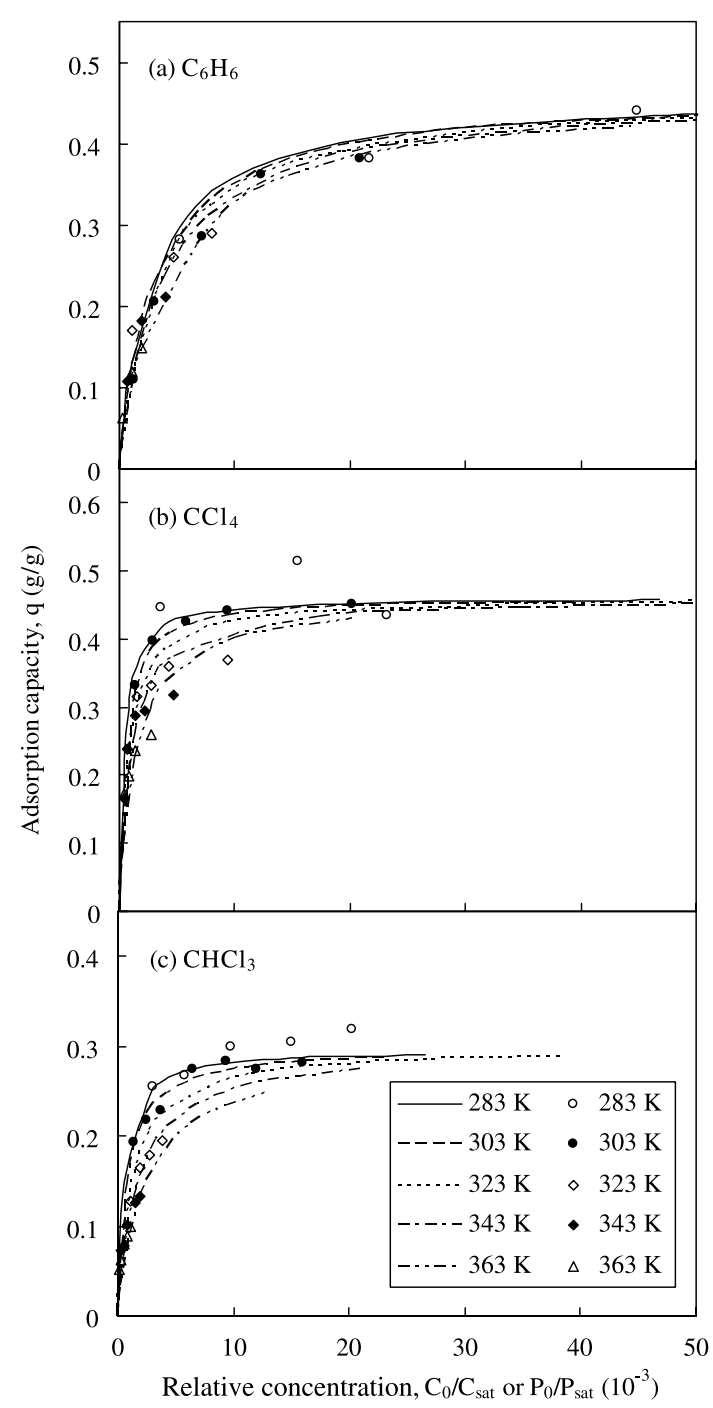

Fig. 4. Prediction of adsorption isotherms (points are experimental data and lines are model predicted).

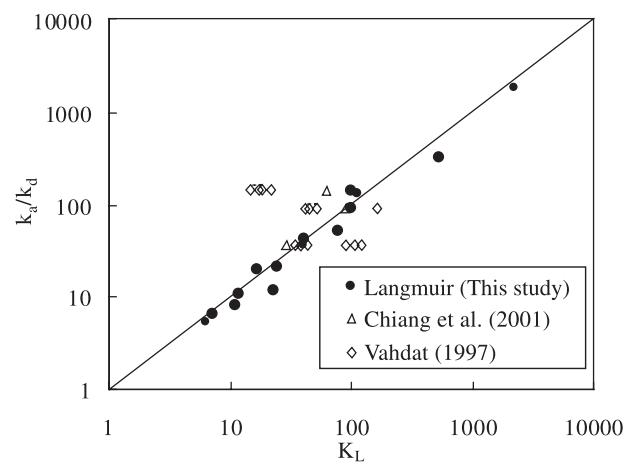

Fig. 5. Relationship of equilibrium constants of Langmuir and adsorption/desorption models.
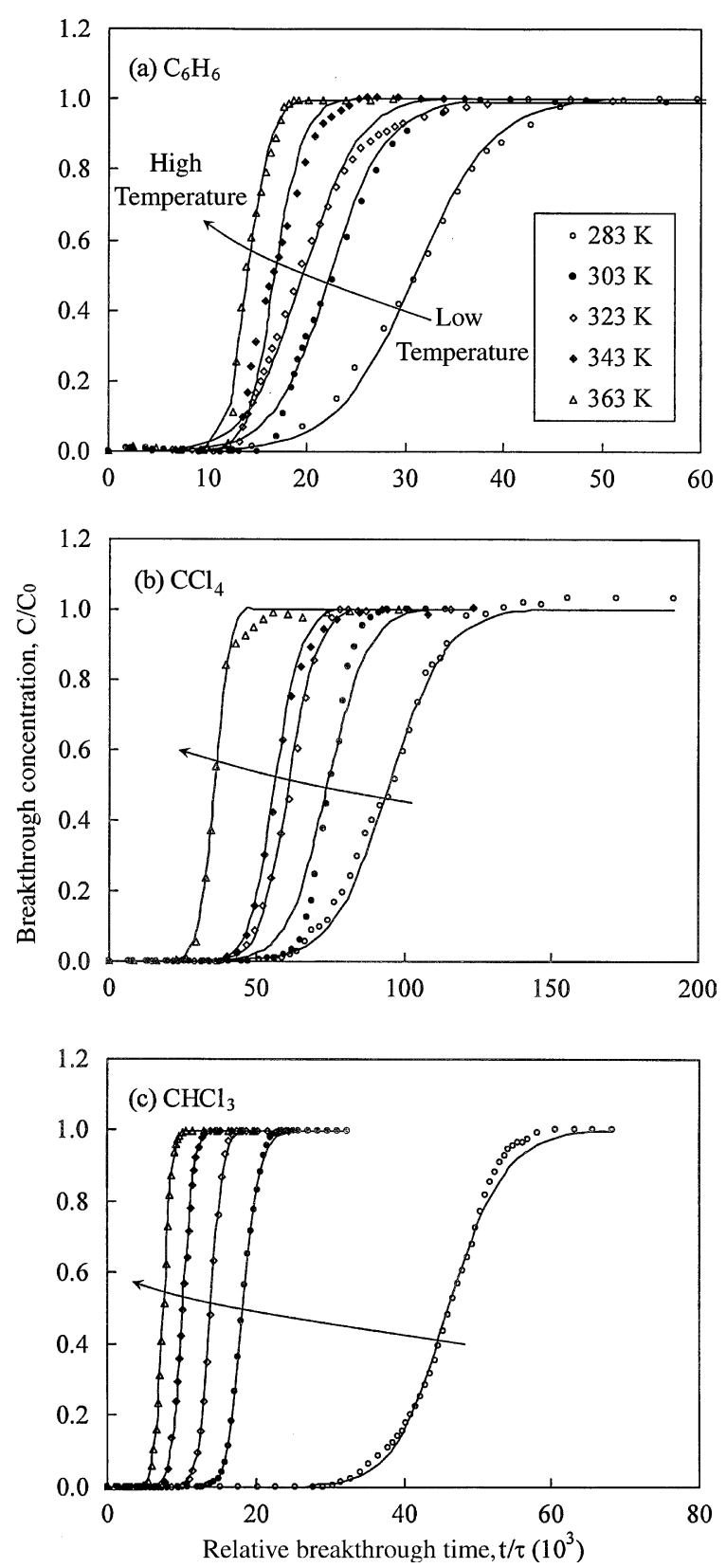

Fig. 6. Prediction of breakthrough curve of adsorption process as a function of temperature (reaction conditions: see Table 2).

\section{Conclusions}

In this study, a BDR model was used to assess the effect of temperature on the adsorption and desorption of three VOCs. Compare with Langmuir isotherm and LDF (with Langmuir) model, the BDR model shown the same trend with both of them, such as $\mathrm{CCl}_{4}$ has a larger $k_{\mathrm{a}} / k_{\mathrm{d}}$ (BDR model) and $K_{\mathrm{L}}$ (Langmuir isotherm) 

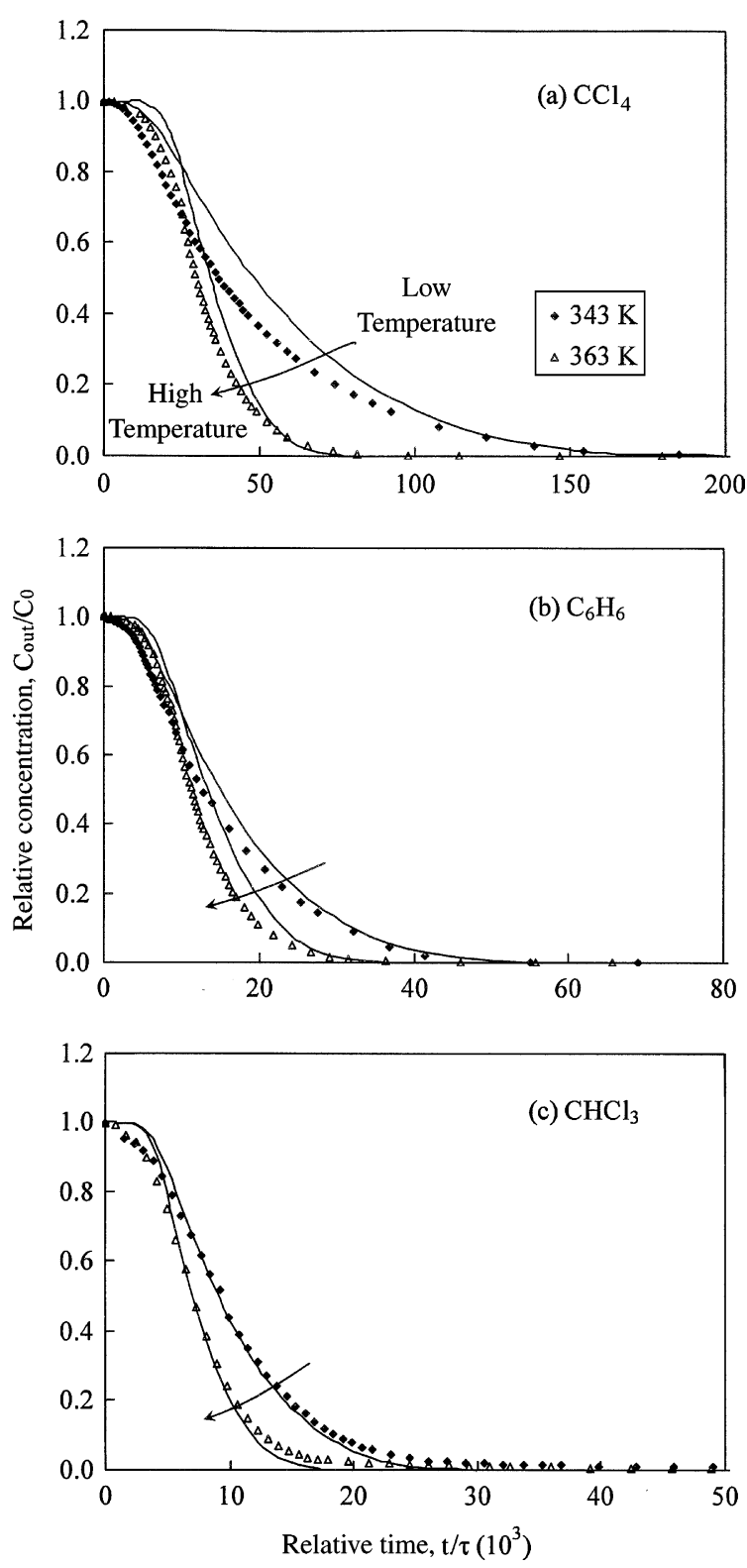

Fig. 7. Prediction of desorption concentration as a function of temperature (reaction conditions: see Table 2).

and $k$ (LDF with Langmuir) than $\mathrm{C}_{6} \mathrm{H}_{6}$ and $\mathrm{CHCl}_{3}$, and the $k_{\mathrm{a}} / k_{\mathrm{d}}$ values of $\mathrm{CCl}_{4}$ and $\mathrm{C}_{6} \mathrm{H}_{6}$ have the same order of magnitude as those reported by Vahdat (1997) and Chiang et al. (2001). Based on these parameters, it is possible to predict the adsorption isotherms and breakthrough curves under various operational conditions. Both experimental and model-predicted data indicate that both the adsorption and desorption rate constants increase whereas equilibrium adsorption constants decreased under high reaction temperatures. The
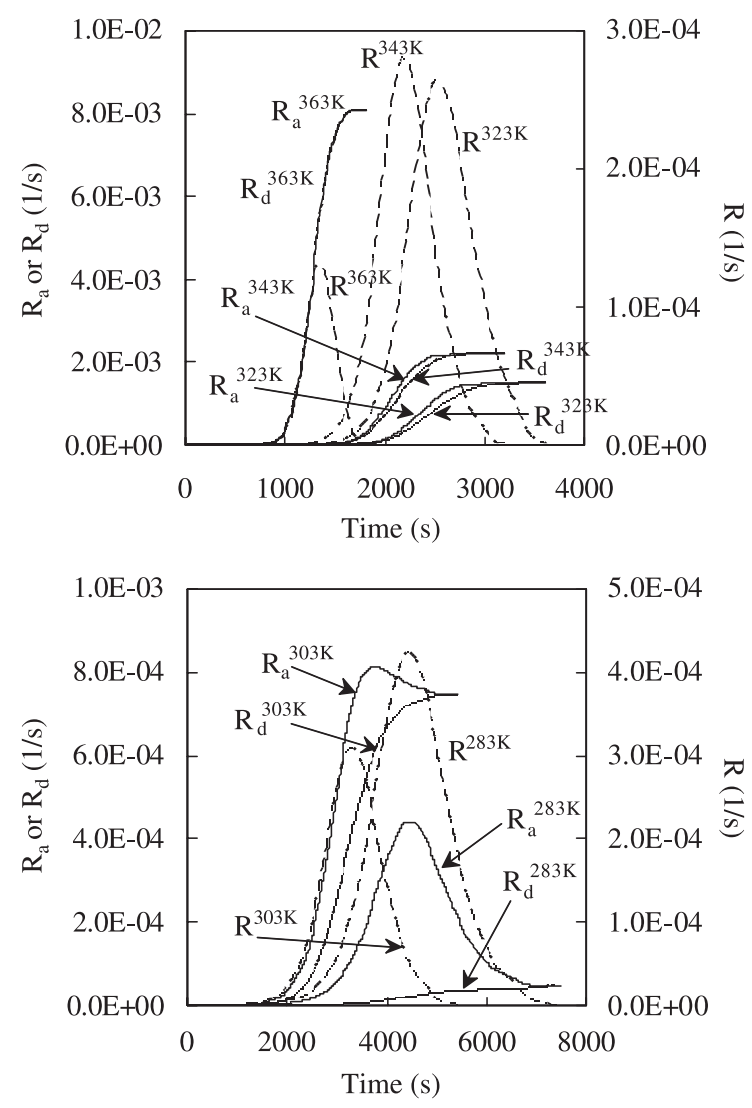

Fig. 8. Adsorption and desorption rate change on adsorption process for $\mathrm{CCl}_{4}$ (reaction conditions: see Table 2).

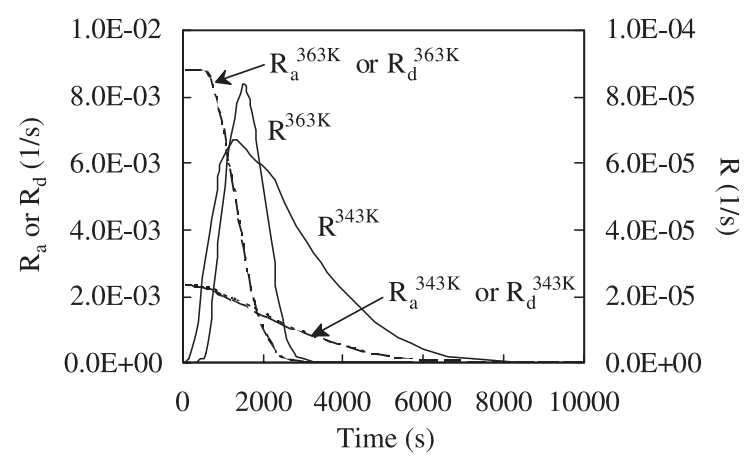

Fig. 9. Adsorption and desorption rate change on desorption process for $\mathrm{CCl}_{4}$ (reaction conditions: see Table 2).

adsorption process is an exothermic process $(\Delta H<0)$; high temperature will decrease the adsorption capacity $\left(q / q_{0}\right)$. From the model prediction, the adsorption rates were slightly higher than the desorption rates at the adsorption process; on the other hand, the adsorption rates were slightly lower than the desorption rates during the desorption process. 


\section{References}

Breysse, P.N., Cappabianca, A.M., Hall, T.A., Risby, T., 1987. Effect of polarity on the adsorption of dichlorobenzene isomers. Carbon 25 (6), 803-808.

Chiang, Y.C., Chiang, P.C., Chang, E.E., 2001. Effects of surface characteristics of activated carbons on VOC adsorption. J. Environ. Eng. 127 (1), 54-62.

Crittenden, J.C., Weber, W.J., 1978. Predictive model for design of fixed-bed adsorbers: single-component model verification. J. Environ. Eng. 104 (2), 433-443.

Dubinin, M.M., 1989. Fundamentals of the theory of adsorption in micropores of carbon adsorbents: characteristics of their adsorption properties and microporous structures. Carbon 27 (3), 457-467.

Gkueckauf, E., 1955. Theory of chromatography. Part 10. Formulae for diffusion into spheres and their application to chromatography. Trans. Faraday Soc. 51 (11), 1540-1551.

Hwang, K.S., Lee, W.K., 1994. The adsorption and desorption breakthrough behavior of carbon monoxide and carbon dioxide on activated carbon. Effect of total pressure and pressure-dependent mass transfer coefficients. Separ. Sci. Technol. 29 (14), 1857-1891.

Jonas, L.A., Rehrmann, J.A., 1972. Kinetics of adsorption of organo-phosphorus vapors from air mixtures by activated carbon. Carbon 10 (6), 657-663.

King, B., Do, D.D., 1996. Measurement of multicomponent adsorption kinetics of gases in activated carbon by a batch adsorber FT-IR technique. Chem. Eng. Sci. 51 (3), $423-$ 439.

Malek, A., Farooq, S., 1996. Comparison of isotherm models for hydrocarbon adsorption on activated carbon. AIChE J. 42 (11), 3191-3201.

Malek, A., Farooq, S., 1997. Kinetics of hydrocarbon adsorption on activated carbon and silica gel. AIChE J. 43 (3), 761-776.

Myers, A.L., Prausnitz, J.M., 1965. Thermodynamics of mixedgas adsorption. AIChE J. 11 (1), 121-126.

Myers, A.L., Valenzuela, D.P., 1986. Computer algorithm and graphical method for calculating adsorption equilibria of gas mixtures. J. Chem. Eng. Jpn. 19 (5), 392-396.

Pigram, P.J., Lamb, R.N., Hibbert, D.B., Collins, R.E., 1994. Modeling of the desorption behavior of microporous amorphous hydrogenated carbon films. Langmuir 10 (1), 142-147.

Vahdat, N., 1997. Theoretical study of the performance of activated carbon: in the presence of binary vapor mixtures. Carbon 35 (10), 1545-1557.

Vahdat, N., Swearengen, P.M., Johnson, J.S., Priante, S., Mathews, K., Neihart, A., 1995. Adsorption capacity and thermal desorption efficiency of selected adsorbents. Am. Ind. Hyg. Assoc. J. 56 (1), 32-38.

Wood, G.O., 1992. Activated carbon adsorption capacities for vapors. Carbon 30 (4), 593-599.

Yoon, Y.H., Nelson, J.H., 1984. Application of gas adsorption kinetics: I. A theoretical model for respirator cartridge service life. Am. Ind. Hyg. Assoc. J. 45 (8), 509-516. 